"This is the peer reviewed version of the following article: [FULL CITE], which has been published in final form at [Link to final article using the DOI]. This article may be used for non-commercial purposes in accordance with Wiley Terms and Conditions for Self-Archiving."

\title{
Deep cavitand self-assembled on Au NPs-MWCNT as highly sensitive benzene sensing interface
}

Pierrick Clément, Saša Korom, Claudia Struzzi, Enrique J. Parra, Carla Bittencourt, Pablo Ballester*, Eduard Llobet*

P. Clément, Dr. E. J. Parra, Pr. E. Llobet

MINOS-EMaS, Universitat Rovira i Virgili, Avenida Paisos Catalans 26, 43007, Tarragona, Spain

E-mail: eduard.llobet@urv.cat

S. Korom, Prof. P. Ballester

Institute of Chemical Research of Catalonia (ICIQ), Av. Països Catalans 16, 43007,

Tarragona, Spain

E-mail: pballester@iciq.es

C. Struzzi, Dr. C. Bittencourt

ChIPS, Université de Mons, Place du Parc 23, 7000 Mons, Belgium

Keywords: quinoxaline-walled deep cavitand, multi-walled carbon nanotubes, oxygen plasma treatment, gold nanoparticle, benzene.

The unprecedented sensitivity and partial selectivity of quinoxaline-walled thioether-legged deep cavitand functionalized multiwall carbon nanotubes toward traces of benzene vapors is presented. The cavitand is grafted onto gold nanoparticle (Au-NP) decorated oxygen plasma treated multiwall carbon nanotubes (O-MWCNT) by a self-assembled monolayer process affording a product referred to as cav-Au-MWCNT. The reported technique is suitable for the mass production of hybrid nanomaterials at low cost. The cav-Au-MWCNT resistive gas sensor operates at room temperature and shows an outstanding performance toward traces of benzene vapors. The detection of $2.5 \mathrm{ppb}$ of benzene in dry air is demonstrated with a limit of detection (LOD) near 600 ppt. For the first time, it is shown that a CNT nanomaterial can effectively sense the extremely harmful benzene molecule with higher sensitivity than toluene or $o$-xylene at the trace levels. The cavitand is well suited for binding benzene, which, being in close proximity to the MWCNT, affects its density of states (DOS) shifting the Fermi level away from the valence band. The binding of benzene is transduced in a diminution of 
MWCNT conductance. Furthermore, the inclusion of benzene is fully reversible at room temperature, implying that the sensor can operate at very low power consumption.

\section{Introduction}

Benzene is a non-polar six-membered ring aromatic hydrocarbon with molecular formula $\mathrm{C}_{6} \mathrm{H}_{6}$, with dimensions of ca. $6.0 \times 3.5 \AA$ and a volume of $120 \AA^{3}$. It belongs to the BTEX (Benzene, Toluene, Ethylbenzene and Xylene) group of compounds. The components of this group feature similar structures but quite different toxicological properties. Benzene is listed among the most harmful volatile organic compounds (VOC). It has a highly flammable and toxic vapors and is recognized as a human carcinogen by the US Environmental Protection Agency and by the European Commission. ${ }^{[1]}$ Long term exposures to relatively low concentrations of benzene over months or years leads to severe hemotoxic effects such as aplastic anemia and pancytopenia and to acute non-lymphocytic leukemia. ${ }^{[2]}$ In the last ten years, the permissible exposure limit has been lowered from $10 \mathrm{ppm}$ to $100 \mathrm{ppb}{ }^{[3]}$ According to the Directive 2008/50/EC of the European Parliament and of the Council of May 2008, the limit value for the annual average exposure to benzene is $5 \mu \mathrm{g} \mathrm{m}^{-3}(1.6 \mathrm{ppb}){ }^{[4]}$

Nowadays, several methods for detecting benzene traces are in use. Most of them involve pumping of the sample and subsequent analysis by employing colorimetric detector tubes or gas chromatography (GC-FID, GC-MS). These methods are bulky, expensive and do not allow implementation for a continuous monitoring of benzene traces. In the last few years, pre-concentration methods and GC equipment have been improved in terms of miniaturization and with a LOD reaching the ppb level for benzene. ${ }^{[5]}$ However, such systems are still limited by their long response time, high power consumption and high cost. Alternatively, the use of portable photoionization detectors (PID) has been reported as well, but PID devices are not selective to benzene and give a total reading for 
VOCs. The only option to make PID more selective for benzene is to utilize a single-use, disposable and rather expensive filter at the inlet port of the device what would result in a dramatic cost increase of running benzene measurements. Benzene is present in the petrochemical industry, land reclamation, petroleum coke oven operators, petrol stations, motor vehicle repair stations, roadside works and many other industries. Their activity may result in active exposure to benzene and would clearly benefit from affordable, portable, highly sensitive and selective detectors able to run continuous measurements.

The fact that benzene lacks active chemical functional group(s) renders its trace detection a challenge by employing miniaturized sensors. For a few decades, many studies have been focused on the use of weak and reversible interactions for the development of receptors for the selective complexation of aromatic compounds via "host-guest" strategy. Cram et al. pioneered host-guest studies using deep cavitands derived from resorcin[4]arene scaffolds. ${ }^{[6]}$ The shallow aromatic cavity present in the resorcin[4]arene parent compound was further elaborated by installing bridging groups at the upper rim. Quinoxaline-bridged resorcin[4]arene cavitands are known to bind aromatic guests (e.g. benzene, toluene, fluorobenzene), not only in the liquid, but also in the gas phase. ${ }^{[7]}$ The attractive $\mathrm{CH}-\pi$ and $\pi-\pi$ interactions established between the receptor and the included aromatic compound constitute the main driving forces responsible for the formation of inclusion complexes. Thoden et al. modified the alkyl substituents at the lower rim of the cavitands with thioether functions in order to anchor the receptors on a gold surface. ${ }^{[8]}$ The improvements achieved in the synthesis of the cavitands together with the possibility to deposit them as self-assembled monolayers on different solid substrates led to the emergence of new strategies in the design of sensors devices. ${ }^{[9]}$ Consequently, several approaches for the detection of aromatic compounds both in liquid and gas phases have been reported. The recognition event (formation of a 
host-guest complex) was transduced in changes on optical properties (surface plasmon resonance, ${ }^{[10]}$ fluorescence spectroscopy ${ }^{[11]}$ ) or in mass changes in the case of resonant devices (quartz crystal micro balance sensor, ${ }^{[12]}$ or a PZT piezoelectric device ${ }^{[13]}$ ). For

these devices, the reported LOD for BTEX ranges from 50 to hundreds of ppm.

Resorcin[4]arene cavitands have also been used as absorbent materials in preconcentrator devices coupled to a $\mu$-GC column for analyte separation. Furthermore, the detection of analytes was performed by a metal oxide gas sensor or mass spectrometer. ${ }^{[14]}$ In these examples the detection limit for BTEX was found to be in the ppb range. ${ }^{[15]}$ Recently, resorcin[4]arene cavitands were covalently attached to carbon nanotubes (CNTs) that acted as transducers ${ }^{[16]}$ for conductance measurement in the

solid-liquid sensor interphase. CNTs have attracted considerable interest as nanomaterial for sensing in solid-gas interphase. ${ }^{[17]}$ They are particularly sensitive to local chemical environment of the gas phase. ${ }^{[18]}$ The functionalization of CNTs with metal-NPs has been exploited to enhance the sensitivity of the material for benzene sensing, reaching an LOD of about 50 ppb in dry air. ${ }^{[19]}$ The metal-NP-CNT system acts as the transduction unit of the adsorbed event in a resistive gas sensor. Indeed, the interaction of the material with molecules of benzene in the gas phase results in an electronic charge transfer process between the organic molecule and the metal-NP-CNT nanomaterial. This affects the position of the Fermi energy and, hence, the conductivity of the detection unit. The different used metals show different response towards a variety of gas or vapor molecules, which can be used to improve the selectivity. ${ }^{[20]}$ However, the decoration of CNTs with metal nanoparticles for improving the device's selectivity has been implemented with limited success because these nanomaterials show similar sensitivity to variety of aromatic compounds and heating is needed to recover the sensor baseline. ${ }^{[19 a]}$ 
Here we describe a simple experimental procedure to prepare an unprecedented type of resistive gas sensing device that employs gold nanoparticle (Au-NP) decorated oxygenfunctionalized multiwall carbon nanotubes (O-MWCNTs). The Au-NPs are functionalized after deposition on the O-MWCNTs with quinoxaline-walled thioetherlegged cavitand 4 (Figure 1.) leading to highly sensitive molecular recognition of benzene vapors. Additionally, we explored the sensitivity of the sensor towards others air pollutants such as toluene, $o$-xylene, carbon monoxide, nitrogen dioxide and ethanol vapors in order to evaluate cross sensitivity. The gas sensing mechanism is discussed on the basis of the experimental findings and the mechanism of inclusion complex (benzene $\subset$ 4) formation in the light of reported, structurally related systems in solutions.

Figure 1.

\section{Results and discussion}

\subsection{Anchoring of the cavitand on MWCNTs}

The gas sensitive, hybrid nanomaterial was prepared by employing a three-step approach. In the first step MWCNTs were treated with oxygen in plasma to create surface oxygenated defects quoted in literature as $\mathrm{VO}_{2}$ (oxygenated vacancies) and $\mathrm{V}_{2} \mathrm{O}_{2}$ (oxygenated double-vacancies); these carbon nanotubes are referred to as $\mathrm{O}$ MWCNT. ${ }^{[21]}$ In the second step, the O-MWCNTs were decorated with Au nanoparticles by means of RF-sputtering and finally, in the third step the Au-decorated and oxygen plasma treated MWCNTs (referred to as Au-MWCNT) were functionalized with a selfassembled monolayer of cavitand 4 to produce a desired hybrid material (referred to as cav-Au-MWCNT). These steps are illustrated in 


\section{Figure 2.}

The sensing properties of the cav-Au-MWCNTs when operated at room temperature were studied by exposing them to different chemical environments (benzene, toluene, $o$ xylene, carbon monoxide, ethanol and nitrogen dioxide) at different concentrations. For comparison, the results obtained in the gas-sensing measurements performed on AuMWCNT sensors are also reported.

\subsection{Step by step characterization}

The morphology and chemical composition of the active layers were characterized using transmission electron microscopy (TEM, Figure 3. and Figure 4.) and X-ray photoelectron spectroscopy (XPS, Figure 5.). The homogeneous dispersion of Au nanoparticles (average diameter $\sim 2 \mathrm{~nm}$ ) on MWCNTs is illustrated in Figure 3. Figure 4a. and Figure 4b. show that SAM procedure, implemented for Au-MWCNTs functionalization with the cavitand 4, promoted aggregation of the previously deposited Au-NPs (with cluster diameters ranging from 10 to $15 \mathrm{~nm}$ ). The immersion of Au-MWCNTs in a chloroform solution of the cavitand $4(0.5 \mathrm{mM})$ under mild heating $\left(60^{\circ} \mathrm{C}\right)$, as required by the SAM technique,${ }^{[17]}$ favored both the cavitand assembly on the Au-NPs and their aggregation on the MWCNTs. We performed XPS analyses for O-MWCNT, Au-MWCNT, cav-Au-MWCNT and cavitand 4 samples.

Figure 3.

Figure 4. 
In Figure 5a. we show the XPS spectra acquired for (1) $\mathrm{O}_{2}$ plasma treated MWCNTs, (2) gold decorated O-MWCNTs and (3-4) cav-Au-MWCNTs samples. The XPS spectra for the cavitand 4 alone (5) is included to assist in the identification of important features in the XPS spectra of cav-Au-MWCNTs samples differing in the time used for the construction of the SAM: $13 \mathrm{~h}(3)$ and $24 \mathrm{~h}(4)$. All samples contained the oxygen peak corresponding to $\mathrm{O}_{1 \mathrm{~s}}$ (Figure 5a.) due to the oxygen plasma treatment experienced by the MWCNTs. All Au-decorated samples showed the characteristic $\mathrm{Au}_{4 \mathrm{~d}}$ and $A u_{4 \mathrm{f}}$ doublets. The presence of the cavitand 4 on cav-Au-MWCNT samples, and therefore, the success of the functionalization protocol, was confirmed by the observation of the $\mathbf{N}_{1 \mathrm{~s}}$ peak located at $399 \mathrm{eV}$. This peak is diagnostic of the presence of organic nitrogen and appears only in the spectra of the cavitand and cav-Au-MWCNT samples (Figure 5b). We obtained similar values of relative atomic concentrations $([\mathrm{N}]=3 \%$ and $2 \%$ at. conc.)

for the samples treated in the SAM process for 13 and $24 \mathrm{~h}$, curves (3) and (4) respectively, indicating that $13 \mathrm{~h}$ are sufficient to fully functionalize the Au-MWCNTs with cavitand 4.

Figure 5.

The resistive sensor consist of a hybrid nanomaterial, which comprises both recognition and transducer elements, embedded in a standard electronic device. With a cavity depth in the order of $8.3 \AA$, a quinoxaline-bridged cavitand 4 can completely include one BTEX molecule and form a 1:1 host-guest complex mainly stabilized by $\pi-\pi$ and $C H-\pi$ interactions. ${ }^{[23]}$ The Au-MWCNTs are selected as an integral part of the resistive sensor. They provide sites where the thioether groups of the cavitand 4 can be anchored. The 
oxygen plasma treatment resulted in the presence of oxygenated defects on the outer wall of MWCNTs. Such defects help gripping, nucleating and stabilizing Au-NPs. Conversely, pristine carbon nanotubes shows very weak interactions with the Au-NPs by establishing interactions with the p-orbitals of the $\mathrm{sp}^{2}$ carbons of the network. ${ }^{[24]}$ Theoretical studies have shown that $\mathrm{Au}$ atoms get trapped at $\mathrm{VO}_{2}$ defects (oxygenated vacancies), which are the most abundant in oxygen plasma treated MWCNTs compared to $\mathrm{V}_{2} \mathrm{O}_{2}$ defects (oxygenated di-vacancies), with a binding energy that is $0.55 \mathrm{eV}$ higher than the binding energy of Au decorated pristine MWCNT. ${ }^{[25]}$ DFT calculations indicated that the presence of oxygen atoms at the functionalized site reduces the HOMO (Highest Occupied Molecular Orbitals)-LUMO (Lowest Unoccupied Molecular Orbitals) gap to $0.82 \mathrm{eV}$. This reduction can be explained by the higher density of states near the Fermi level, arising from the overlap of the $2 p$ electrons of the $O$ atoms and the p electron system of the nanotube. ${ }^{[26]}$ MWCNTs can either be metallic or semiconducting depending on the axial chirality of the individual shells and depending on the intershell interaction. A detailed description of their conductance is rather complex, but the main contribution to charge conduction near the Fermi energy level is given by the outer tube. Mats of MWCNTs, such as those employed in the present experiment, consist of a mixture of metallic and semiconducting tubes. Macroscopically, these mats behave as mild $\boldsymbol{p}$-type semiconductors since their conductance increases or decreases upon adsorption of electron-accepting or donating molecules, respectively. ${ }^{[19 b,}$ ${ }^{25]}$ Furthermore, according to DFT calculations, the decoration with Au-NPs slightly perturbs the band structure of MWCNTs causing a small shift of the Fermi level energy toward lower energies, which is equivalent to a $p$-doping of the tubes (i.e. there is a small electronic charge transfer from the tube to the Au-NP). ${ }^{[27]}$ Finally, since the MWCNT mat consists of defective nanotubes, ${ }^{[28]}$ its resistance is mostly influenced by the resistance of individual nanotubes and not by the inter-nanotube or the electrode- 
nanotube junctions. ${ }^{[29]}$ Upon formation of the host-guest complex, BTEX $\subset$ cavitand 4

(molecular recognition event), and by assuming the existence of a close proximity between the walls of the cavitand 4 and the surface of the MWCNT, we are prone to speculate that the overall resistance of the MWCNT mat will be influenced (transducer function).

\subsection{Gas sensing properties}

Four cav-Au-MWCNT sensors and two Au-MWCNT sensors were employed for the study of the gas sensing capabilities. Au-MWCNT sensors were fabricated employing the same conditions to those used for cav-Au-MWCNT sensors, but the last step (i.e. the functionalization with cavitand 4 via SAM) was performed just with pure chloroform to induce the aggregation of the Au-NPs on the same level. Each measurement was repeated at least three times. The typical response and recovery cycles of a cav-AuMWCNT sensor towards increasing concentrations of benzene in dry air are shown in Figure 6a. The signal to noise ratio for the sensor response was high. The response and recovery cycles were recorded while the sensor was operated at room temperature and the sensing process was demonstrated to be reversible. During the recovery phase, pure dry air was flown resulting in full baseline resistance recovery. The measurement period lasted for about six months in which not significant changes in the baseline resistance nor in sensitivity were observed. In short, the sensor response is reversible and not affected by low-term drift. The typical calibration curves for the cav-Au-MWCNT sensor exposed to benzene, toluene, $o$-xylene, ethanol and carbon monoxide are depicted in Figure 6a. This sensor showed significantly higher sensitivity to benzene than to the other tested pollutants. At $100 \mathrm{ppb}$ level of benzene, the sensor is seven and thirty times more responsive than to toluene or $o$-xylene, respectively. Furthermore, the slope of the calibration curve (i.e. sensitivity) was calculated for the two lowest tested concentrations 
and was found to be much higher in the case of benzene $\left(4.2 \times 10^{-3} \% \mathrm{ppb}^{-1}\right)$ than for toluene $\left(1.1 \times 10^{-4} \% \mathrm{ppb}^{-1}\right)$ and $\mathrm{o}-x y l e n e ~\left(3.3 \times 10^{-5} \% \mathrm{ppb}^{-1}\right)$. Therefore, the sensor should be able to detect with high sensitivity traces of benzene in the presence of toluene and/or $o$-xylene. The responses to ethanol and carbon monoxide were significantly lower. In summary, the sensor is partially selective toward benzene and a possible strategy for further enhancing selectivity (beyond the scope of this paper) would be to use an array of sensors with different sensitive layers together with a pattern recognition engine. ${ }^{[30]}$ Taken together, these results demonstrated an unprecedented high sensitivity of the cavAu-MWCNT sensor for benzene. The different species whose sensing is reported in Figure 6b. are electron donors. The overall resistance of the cav-Au-MWCNT mat increased when exposed to any of these species. Macroscopically, this implies that our hybrid nanomaterial retains the $p$-type semiconductor behavior observed for bare or Au-MWCNT mats.

Figure 6.

As often encountered in gas sensors, sensitivity and dynamics of response can be further enhanced by increasing the gas flow rate (Figure 7a.). When the flow is increased, layer gradient that defines a profile of laminar flow attenuated in the boundary layer at the sensor surface. This allowed a better diffusion of benzene towards the sensing layer, and results in an increase of the concentration of the inclusion complexes BTEX $\subset$ cavitand 4 on the surface of MWCNTs mats and therefore a higher sensor response was observed. ${ }^{[31]}$ Up to 2.5 ppb of benzene in air can easily be detected at $400 \mathrm{~mL} \mathrm{~min}{ }^{-1}$ (Figure 7b.). To the best of our knowledge, this is the first system that can detect such a low level of benzene in the gas phase by employing a CNT-based material. 


\section{Figure 7.}

Even at very low benzene levels, the response of the sensor was highly reproducible (Figure 8.). Thanks to the low levels of noise in the response signals, the theoretical LOD for the sensors was calculated to be 600 ppt, which corresponds to a sensor response three times higher than the level of the noise. ${ }^{[32]}$ The responses to benzene provided by the Au-MWCNT sensor were tested for comparison. The Au-MWCNT sensor was not responsive to benzene vapor levels under $60 \mathrm{ppb}$ in dry conditions. Even at this concentration (60 ppb), the response was low. This observation is in good agreement with theoretical findings that predict a very weak binding energy and the lack of charge transfer between the benzene molecule and the Au-MWCNTs system. These results supported the idea that cavitand 4, in junction with Au-NPs and MWCNTs, were necessary for the high sensitivity measured for benzene.

Figure 8.

\subsection{Gas sensing mechanism}

In Figure 9., we portray simplified scheme of the plausible mechanisms for benzene sensing and recovery. We propose that the interior of cavitand 4 , anchored to the surface of cav-Au-MWCNT, is initially occupied by an air molecule (e.g. nitrogen). This status of the system is referred to as $\mathbf{N}_{2} \subset$ cav-Au-MWCNT. The inclusion of guest in the cavity of 4 is a dynamic process allowing a constant chemical exchange, between free and included air molecules. When the $\mathrm{N}_{2} \subset$ cav-Au-MWCNT system is exposed to air contaminated with benzene vapors, some of the cavitands bind a benzene molecule. 
Cavitand 4 shows higher affinity for benzene than nitrogen owing to the establishment of additional interactions ( $\mathrm{CH}-\pi$ and $\pi-\pi)$ between the benzene and the walls of the cavitand. In solution, the exchange process is referred to as "hostage-exchange mechanism" and occurs via significant conformation changes involving moving from the vase to the kite conformation of the cavitand, a process with an energy barrier of $\mathbf{1 1 . 6}$ kcal $\mathrm{mol}^{-1}{ }^{[33]}$ The kite conformation of the $\mathrm{N}_{2} \subset \mathrm{cav}-\mathrm{Au}-\mathrm{MWCNT}$ allows an easy access of a guest molecule (benzene) to the shallow cavity of the cavitand and substitution of the

previously bound guest molecule $\left(\mathrm{N}_{2}\right) \cdot{ }^{[33 \mathrm{~b}]}$ Upon guest-exchange, the cavitand's walls fold back to vase conformation producing a new host-guest inclusion complex (referred to as benzene $\subset$ cav-Au-MWCNT). In this way, two inclusion complexes are present on the surface of cav-Au-MWCNT, one with an included nitrogen molecule and the other with a benzene molecule (Figure 9., marked with *).

Figure 9.

To explain the transduction mechanism we hypothesized two plausible types of communication between the cavitand and the MWCNT (Figure 10.). The first type of communication would involve gold mediation between the $\pi$-electron cloud(s) of the quinoxaline wall(s) from the cavitand and the $\pi$-electron clouds of MWCNT (referred to as $\pi$-Au- $\pi$ communication). The second type of communication would exclude gold mediation and would occur between cavitand molecules located on the edge of Au-NPs whose quinoxaline wall(s) are in direct contact with the MWCNT surface allowing $\pi-\pi$ stacking interaction (referred to as $\pi-\pi$ communication). In both cases, the $\pi$-electron density of the quinoxaline walls of the cavitand must be affected by the nature of the included guest molecule (benzene or air molecule). Upon inclusion of a benzene molecule, which also possesses delocalized $\pi$-electrons, additional $\pi$ - $\pi$ interactions can be 
established between benzene and the cavitand wall. As a consequence, the $\pi$-electron density of the cavitand walls is modified. This electron density changes are translated onto the $\pi$-electron clouds of the MWCNT through a charge-transfer/electron-transfer mechanisms. This results in hole depletion and decrease in the conductance of MWCNT, experimentally measured as an increase in sensor resistance. Conversely, the stream of pure air modifies the equilibria between benzene $\subset$ cav-Au-MWCNT and $\mathrm{N}_{2} \subset \mathrm{cav}-\mathrm{Au}$ MWCNT. The formation of the latter inclusion complex recovers the initial state of the sensor and therefore the baseline resistance of the sensor.

Figure 10.

The lower response displayed by the sensor (reduced increase of resistance) towards the more electron-rich toluene and $o$-xylene molecules, which based on the sensing mechanism proposed above, must imply a reduction of the electron-donating capabilities of their inclusion complexes with the cavitand 4, is not clear to us. On the one hand, published binding experiments demonstrated that toluene and $o$-xylene, in fact, bind more strongly than benzene inside the cavitand 4 , both in the liquid and gas phase. ${ }^{[15 a}$, ${ }^{23]}$ On the other hand, the dipole moments of benzene, toluene and o-xylene are $0,0.36$ and $0.64 \mathrm{D}$, respectively. We speculate that the lack of dipole moment exhibited by benzene could be somehow responsible of the different electron donating properties assigned to its host-guest complex (benzeneccav-Au-MWCNT). Clearly, the verification of this hypothesis must await the results of further experimental and theoretical studies that are beyond the scope of the present work.

Nitrogen dioxide gas, belongs to the so-called $\mathrm{NO}_{\mathrm{x}}$ and is a toxic gas released from combustion facilities and automobiles. ${ }^{[34]}$ Thus, it is present in atmosphere and its effect has to be studied on our sensors. The adsorption of $\mathrm{NO}_{2}$ was reported to occur either over $\mathrm{Au}-\mathrm{NP}$ 
or over oxygenated defects and exhibits strong response. ${ }^{[35],[27]}$ The first-principle modeling of gas adsorption on $\mathrm{Au}-\mathrm{MWCNT}$ revealed that $\mathrm{NO}_{2}$, a polar molecule with partial positive charge localized on the nitrogen atom and partial negative charge divided among oxygen atoms, is attracted to Au-NPs by its nitrogen atom. The computed binding energies and bond lengths showed that $\mathrm{NO}_{2}$ strongly interacts with $\mathrm{Au}-\mathrm{NPs}$ and that the molecule accepted a significant amount of electronic charge from the Au-MWCNT system. This hypothesis is consistent with the well-known electron accepting nature of this molecule. ${ }^{[27]}$ Quantum electron transport calculations revealed that the adsorption of a single $\mathrm{NO}_{2}$ molecule on the surface of the Au-NP resulted in a remarkable decrease of the Fermi energy level of the AuMWCNT system. ${ }^{[27]}$ This is consistent with the decrease in resistance that we observed for Au-MWCNT mats in the presence of $\mathrm{NO}_{2}$.

The response of both cav-Au-MWCNT and Au-MWCNT sensors to different concentrations of $\mathrm{NO}_{2}$ was also studied. The calibration curve of $\mathrm{NO}_{2}$ detection for a cavAu-MWCNT and Au-MWCNT sensors operated at room temperature can be found in the Supporting Information. The response towards $\mathrm{NO}_{2}$ displayed by cav-Au-MWCNT sensor is about two times lower than that exhibited by the Au-MWCNT sensor. However, $\mathrm{NO}_{2}$ cross-sensitivity of cavitand-functionalized sensors remains noticeable. The cav-AuMWCNT may remain somewhat responsive to $\mathrm{NO}_{2}$ because this molecule can be adsorbed directly onto Au-NPs. However, the important decrease in the response toward $\mathrm{NO}_{2}$ observed for cav-Au-MWCNTs in comparison to that of Au-MWCNTs indicated that the presence of the cavitand significantly reduced the affinity of Au-NPs to adsorb $\mathrm{NO}_{2}$ molecules. From a practical point of view, if the detection of benzene should be performed in an environment in which the presence of trace levels of nitrogen dioxide are likely, a detector comprised of two sensors, namely one cav-Au-MWCNT 
sensor and one Au-MWCNT sensor could be used for benzene level correction. Further details on this strategy are given in the Supporting Information.

Ambient moisture plays an important role in the response of chemiresistors. ${ }^{[36]}$ Therefore, a new set of measurements was perfomed in which trace concentrations of benzene, toluene or $o$-xylene in a flow of dry synthetic air were humidified to $10 \%, 25 \%$ and $60 \%$ of relative humidity (R.H.) Taking into account that the pressure was 1 atm and the temperature $22{ }^{\circ} \mathrm{C}$, the relative humidity tested corresponds to levels that ranged between 2,630 and 15,980 ppm of water, i.e. 3 to 5 orders of magnitude higher than the concentrations of the aromatic VOCs present in the mixtures. The presence of moisture affected the sensitivity of the cavitand-Au-MWCNT sensor toward VOCs. Response and recovery cycles for benzene under humid conditions together with calibration curves can be found in the Supporting Information. According to these results, the sensitivity of the sensor toward benzene (i.e. slope of the calibration curve) is $4.20 \% \mathrm{ppm}^{-1}$ under dry conditions and changed to $1.41 \% \mathrm{ppm}^{-1} @ 10 \%$ R.H., $0.48 \%$ ppm $^{-1} @ 25 \%$ R.H and $0.45 \%$ ppm $^{-1} @ 60 \%$ R.H. Taken together, these results indicated that the presence of moisture affected significantly the limit of detection (LOD) of the sensor for benzene. While the benzene LOD remains below $20 \mathrm{ppb}$ for R.H. up to $25 \%$, it rises to about $50 \mathrm{ppb}$ at $60 \%$ R.H. In case of toluene or $o$-xylene, the presence of moisture resulted in the cav-Au-MWCNT sensor not displaying any measurable response for both aromatic VOCs up to at concentrations of 5,000 ppb (i.e., the partial selectivity is not destroyed by the presence of humidity). Two possible strategies can be exploited to overcome the loss in benzene sensitivity caused by ambient moisture. The first option would involve dehumidification by employing inexpensive filters containing polymers such as polyacrylate, polypyrrole or sodium polyacrylate salts, which selectively absorb polar compounds (i.e. water) from the input gas flow leaving non-polar compounds such as benzene unaffected. This strategy has been 
implemented in solid-phase micro-extraction for quantitative gas or liquid chromatography analysis of environmental samples ${ }^{[37]}$ or in hand-held photo-ionization gas. ${ }^{[38]}$ The second option would involve sensor redesign taking into consideration that the oxygen plasma treatment of MWCNTs used to generate defects at their surface for anchoring Au nanoparticles makes CNTs more hydrophilic. Even if the employed cavitand has a hydrophobic character, oxygenated defects present on the surface of carbon nanotubes can be responsible for sensor moisture cross-sensitivity. Alternative methods for achieving Au decoration of CNT sidewalls have been reported, which accounts on the hydrophobic nature of pristine, non-defective CNTs ${ }^{[39]}$ what could be taken into advantage for reducing effect of ambient moisture to the sensor's response. ${ }^{[40]}$

\section{Conclusion}

In conclusion, a simple technique for functionalize the multiwall carbon nanotubes, in view of designing a gas sensor with a superior performance, has been introduced. A quinoxaline-walled thioether-legged cavitand 4 is attached onto oxygen plasma treated Au-NP decorated MWCNTs. The technique is suitable for the mass production of described hybrid sensing nanomaterial at low production costs, allowing cost-effective commercialization. The cavitand-functionalized MWCNT sensor shows unprecedented high sensitivity toward low levels of benzene in dry air at trace levels. The detection of 2.5 ppb is demonstrated experimentally and a theoretical LOD of $600 \mathrm{ppt}$ was calculated. Furthermore, sensor response towards toluene and $o$-xylene is significantly lower, clearly showing the strong response for benzene, what is the first example of such selective carbon nanotube based material. This was possible thanks to the molecular recognition introduced by quinoxaline-bridged cavitand 4 . The sensor shows significant cross-sensitivity to $\mathrm{NO}_{2}$, but this can be compensated by combining a cav-Au-MWCNT 
sensor with an Au-MWCNT sensor, since the latter is more sensitive to $\mathrm{NO}_{2}$ and while insensitive to benzene levels below $60 \mathrm{ppb}$. The cav-Au-MWCNT sensor response toward aromatic VOCs diminishes as the relative humidity in the gas flow increases. It remains responsive to benzene traces in presence of humidity but it becomes insensitive to toluene or $o$-xylene in the same range of concentrations. Possibilities to avoid the effect of moisture could be the dehumidification of the gas flow by employing a inexpensive filter, or keep the hydrophobic character of MWCNTs by using an alternative route to the oxygen plasma treatment used to anchor gold nanoparticles. Finally, it is worth mentioning that both the detection and the recovery of the baseline are performed at room temperature, which implies that these sensors can operate at very low power consumption. This makes the sensor suitable for being integrated in hand-held portable analyzers, wearable detectors and semi-passive radio frequency identification tags with sensing capabilities or in the nodes of wireless sensor networks with a wide range of potential applications in environmental monitoring, workplace safety or medical devices, among others.

\section{Experimental section}

The cavitand 4 was synthesized following a reported procedure (Error! Reference source not found...). ${ }^{[9 c, 10 a]}$ The synthesis of 4 was accomplished in four steps: (1) acid catalyzed condensation of 10-undecenal with resorcinol to yield the resorcin[4]arene framework 1;

(2) TMS protection of the OH groups in the upper rim of the resorcin[4]arene to afforded cavitand 2; (3) addition of 1-decanethiol to the terminal alkenes of the legs of cavitand 2 with concomitant cleavage of the TMS protecting groups afforded cavitand 3. Finally, (4) base promoted coupling of 3 with 2,3-dichloroquinoxaline produced cavitand 4 (details on the synthesis are reported in the Support information). 
The chemical compositions of O-MWCNT, Au-MWCNT, and cav-Au-MWCNT samples were analyzed using X-ray photoelectron spectroscopy (XPS), VERSAPROBE PHI 5000 from Physical Electronics, equipped with a Monochromatic Al Ka X-Ray. The energy resolution was $0.7 \mathrm{eV}$. For the compensation of built up charge on the sample surface during the measurements, a dual beam charge neutralization composed of an electron gun $(\sim 1 \mathrm{eV})$ and the Argon Ion gun $(\leq 10 \mathrm{eV})$ was used.

MWCNTs were obtained from Nanocyl ${ }^{\mathrm{TM}}$ (3101 grade). They were grown by chemical vapor deposition with purity higher than $95 \%$. Carbon nanotubes were up to $1.5 \mu \mathrm{m}$ long and $9.5 \mathrm{~nm}$ in outer diameter. They underwent an oxygen plasma treatment to clean them from amorphous carbon, to promote their dispersion in an appropriate solvent and to create reactive sites (i.e. oxygenated vacancies, O-MWCNTs) in which metal nanoparticles can nucleate. O-MWCNTs were suspended in chloroform $(0.5 \%$ w/w) and sonicated during $30 \mathrm{~min}$ to uniformly disperse them in the solution, which led to a reproducible CNT density. The prepared suspension was air-brushed on an alumina substrate that comprised of $10 \times 10 \mathrm{~mm}$ screen-printed, Pt-interdigitated electrodes with gap of $500 \mu \mathrm{m}$ between electrodes. During the airbrushing, the substrate was kept at

$100{ }^{\circ} \mathrm{C}$ for achieving fast evaporation of the solvent coupled with the resistance monitoring of the device until it reached the defined value of $5 \mathrm{k} \Omega$. This strategy, which is very similar to the one reported by Zilberman et al., ${ }^{[41]}$ enables us to control both the density of the CNT coating and the amount of O-MWCNTs deposited, ensuring device to device reproducibility. To ensure the complete removal of the solvent and promote adhesion of the MWCNT mat to the substrate, sensors were heated at $150{ }^{\circ} \mathrm{C}$ for $2 \mathrm{~h}$.

The final resistance of thermally-treated sensors was a few hundred of ohms. The next step was decoration of O-MWCNTs with Au-NPs achieving by RF sputtering process conducted at $13.56 \mathrm{MHz}$ with a power of $30 \mathrm{~W}$ under Ar plasma at room temperature, under 0.1 Torr, for $10 \mathrm{~s}$. For the formation of the self-assembled 
monolayer of the deep cavitand, sensor substrates were immersed in a solution $(20 \mathrm{~mL})$ of the cavitand $(0.5 \mathrm{mM})$. The SAM process was conducted at $60{ }^{\circ} \mathrm{C}$ for a period of maximum $24 \mathrm{~h}$. These conditions allowed a reversible adsorption in order to have wellordered assembly of the quinoxaline-walled cavitand $(4) .{ }^{[8 a]}$ Finally, the sensor substrates were cooled to room temperature, rinsed with pure chloroform and dried at $50{ }^{\circ} \mathrm{C}$ during $30 \mathrm{~min}$.

The gas sensing properties of the sensors were measured using a miniaturized Teflon chamber (35 mL). Computer-controlled mass flow meters (Bronkhorst hi-tech 7.03.241) and calibrated gas bottles were used $\left(\mathrm{NO}_{2}, \mathrm{CO}\right.$, ethanol, benzene, toluene, o-xylene all diluted in pure air from Praxair), and pure air from Air Products was used to obtain different concentrations. A continuous flow (100, 200 or $400 \mathrm{~mL} / \mathrm{min})$ was used throughout measurements. The flow were humidified to $10 \%, 25 \%$ and $60 \%$ R.H. by employing an Environics Series 4000 gas mixing system (Environics Inc., Tolland, CT, USA). Once sensors were placed inside the test chamber, they were connected to a multimeter interface, which allowed the real-time reading of the resistance. Sensor response is defined as $\mathrm{SR} \%=\left(\mathbf{R}_{\text {gas }}-\mathbf{R}_{\text {air }}\right) * 100 / \mathbf{R}_{\text {air }}$. Throughout the whole testing period sensors were always operated at room temperature $\left(25^{\circ} \mathrm{C}\right)$. Given the low concentration levels tested, the measurement rig was checked to rule out the presence of contamination in mass-flows and tubing by performing a set of control GC/MS tests (run before, during and after gas measurements). 
[1] a) United States Environmental Protection Agency, Drinking Water Contaminants, http://water.epa.gov/drink/contaminants/index.cfm\#Organic, May, 2009; b) European Commission, Air Quality Standards, http://ec.europa.eu/environment/air/quality/standards.htm, accessed: Feb 16, 2015.

[2] a) R. Baan, Y. Grosse, K. Straif, B. Secretan, F. El Ghissassi, V. Bouvard, L. Benbrahim-Tallaa, N. Guha, C. Freeman, L. Galichet, The lancet oncology 2009, 10, 1143; b) A. FassÒ, G. Arduino, Encyclopedia of Environmetrics 2012; c) D. Dougherty, S. Garte, A. Barchowsky, J. Zmuda, E. Taioli, Toxicology letters 2008, 182, 7; d) R. E. Hester, R. M. Harrison, Volatile organic compounds in the atmosphere, Royal Society of Chemistry, 1995; e) A. P. DeCaprio, CRC Critical Reviews in Toxicology 1999, 29, 283.

[3] The National Institute for Occupational Safety and Health, NIOSH Pocket guide for chemical hazards: Benzene, www.cdc.gov/niosh/npg/npgd0049.html, accessed: Apr 4, 2011 [4] Official Journal of the European Union,50/EC of the European Parliament and of the Council of 21 May 2008 on ambient air quality and cleaner air for Europe, http://ec.europa.eu/environment/air/quality/legislation/existing_leg.htm, accessed: Apr 14, 2008.

[5] a) J. Sun, F. Guan, D. Cui, X. Chen, L. Zhang, J. Chen, Sensors and Actuators B: Chemical 2013, 188, 513; b) C. Liaud, N. Nguyen, R. Nasreddine, S. Le Calvé, Talanta 2014, 127, 33; c) R.-S. Jian, Y.-S. Huang, S.-L. Lai, L.-Y. Sung, C.-J. Lu, Microchemical Journal 2013, 108, 161.

[6] D. J. Cram, S. Karbach, H. E. Kim, C. B. Knobler, E. F. Maverick, J. L. Ericson, R. C. Helgeson, Journal of the American Chemical Society 1988, 110, 2229.

[7] a) M. Vincenti, E. Dalcanale, P. Soncini, G. Guglielmetti, Journal of the American Chemical Society 1990, 112, 445; b) M. Vincenti, E. Dalcanale, J. Chem. Soc., Perkin Trans. $21995,1069$. 
[8] a) E. U. Thoden van Velzen, J. F. Engbersen, D. N. Reinhoudt, Journal of the

American Chemical Society 1994, 116, 3597; b) E. U. Thoden van Velzen, J. F. Engbersen, P. J. de Lange, J. W. Mahy, D. N. Reinhoudt, Journal of the American Chemical Society 1995, 117, 6853; c) E. U. Thoden van Velzen, J. F. Engbersen, D. N. Reinhoudt, Synthesis 1995, $1995,989$.

[9] a) F. Dickert, R. Sikorski, Materials Science and Engineering: $C$ 1999, 10, 39; b) Y.

Yamakoshi, R. R. Schlittler, J. K. Gimzewski, F. Diederich, Journal of Materials Chemistry 2001, 11, 2895; c) V. A. Azov, P. J. Skinner, Y. Yamakoshi, P. Seiler, V. Gramlich, F. Diederich, Helvetica chimica acta 2003, 86, 3648.

[10] a) E. B. Feresenbet, M. Busi, F. Ugozzoli, E. Dalcanale, D. K. Shenoy, Sensor Letters 2004, 2, 186; b) R. Capan, Z. Özbek, H. Göktaş, S. Şen, F. Ince, M. Özel, G. Stanciu, F. Davis, Sensors and Actuators B: Chemical 2010, 148, 358; c) M. Erdoğan, R. Capan, F. Davis, Sensors and Actuators B: Chemical 2010, 145, 66; d) Y. Liu, T. Taira, M. C. Young, D. Ajami, J. Rebek Jr, Q. Cheng, R. J. Hooley, Langmuir 2011, 28, 1391; e) A. Hassan, A. Ray, A. Nabok, F. Davis, Sensors and Actuators B: Chemical 2001, 77, 638; f) E. B. Feresenbet, E. Dalcanale, C. Dulcey, D. K. Shenoy, Sensors and Actuators B: Chemical 2004, 97, 211.

[11] O. B. Berryman, A. C. Sather, J. Rebek Jr, Organic letters 2011, 13, 5232.

[12] a) T. Weiss, K. Schierbaum, U. T. van Velzen, D. Reinhoudt, W. Göpel, Sensors and Actuators B: Chemical 1995, 26, 203; b) J. Hartmann, J. Auge, R. Lucklum, S. Rösler, P. Hauptmann, B. Adler, E. Dalcanale, Sensors and Actuators B: Chemical 1996, 34, 305; c) J. Hartmann, P. Hauptmann, S. Levi, E. Dalcanale, Sensors and Actuators B: Chemical 1996, 35, 154; d) R. Paolesse, C. Di Natale, S. Nardis, A. Macagnano, A. D'Amico, R. Pinalli, E. Dalcanale, Chemistry-A European Journal 2003, 9, 5388; e) O. Mermer, S. Okur, F. Siimer, C. Ozbek, S. Sayin, M. Yilmaz, Acta Physica Polonica-Series A General Physics 2012, 121, 240. 
[13] M. Ferrari, V. Ferrari, D. Marioli, A. Taroni, M. Suman, E. Dalcanale, Sensors and Actuators B: Chemical 2004, 103, 240.

[14] a) F. Bianchi, A. Bedini, N. Riboni, R. Pinalli, A. Gregori, L. M. Sidisky, E. Dalcanale, M. Careri, Analytical chemistry 2014; b) R. Pinalli, T. Barboza, F. Bianchi, C. Massera, F. Ugozzoli, E. Dalcanale, Supramolecular Chemistry 2013, 25, 682.

[15] a) F. Bianchi, R. Pinalli, F. Ugozzoli, S. Spera, M. Careri, E. Dalcanale, New Journal of Chemistry 2003, 27, 502; b) S. Zampolli, I. Elmi, F. Mancarella, P. Betti, E. Dalcanale, G. Cardinali, M. Severi, Sensors and Actuators B: Chemical 2009, 141, 322; c) S. Zampolli, P. Betti, I. Elmi, E. Dalcanale, Chemical Communications 2007, 2790; d) F. Bianchi, M.

Mattarozzi, P. Betti, F. Bisceglie, M. Careri, A. Mangia, L. Sidisky, S. Ongarato, E. Dalcanale, Analytical Chemistry 2008, 80, 6423.

[16] a) M. Dionisio, J. M. Schnorr, V. K. Michaelis, R. G. Griffin, T. M. Swager, E. Dalcanale, Journal of the American Chemical Society 2012, 134, 6540; b) F. Wang, T. M. Swager, Journal of the American Chemical Society 2011, 133, 11181; c) L. Kong, J. Wang, F. Meng, X. Chen, Z. Jin, M. Li, J. Liu, X.-J. Huang, Journal of Materials Chemistry 2011, 21, 11109.

[17] J. M. Schnorr, D. van der Zwaag, J. J. Walish, Y. Weizmann, T. M. Swager, Advanced Functional Materials 2013, 23, 5285.

[18] E. Llobet, Sensors and Actuators B: Chemical 2013, 179, 32.

[19] a) P. Clément, I. Hafaiedh, E. Parra, A. Thamri, J. Guillot, A. Abdelghani, E. Llobet, Carbon 2014, 78, 510; b) R. Leghrib, A. Felten, F. Demoisson, F. Reniers, J.-J. Pireaux, E. Llobet, Carbon 2010, 48, 3477.

[20] R. Leghrib, E. Llobet, Analytica chimica acta 2011, 708, 19.

[21] I. Suarez-Martinez, C. Bittencourt, X. Ke, A. Felten, J. Pireaux, J. Ghijsen, W. Drube, G. Van Tendeloo, C. Ewels, Carbon 2009, 47, 1549. 
[22] D. J. Cram, M. E. Tanner, C. B. Knobler, Journal of the American Chemical Society 1991, 113, 7717.

[23] P. Soncini, S. Bonsignore, E. Dalcanale, F. Ugozzoli, The Journal of Organic Chemistry 1992, 57, 4608.

[24] Y. Zhang, N. W. Franklin, R. J. Chen, H. Dai, Chemical Physics Letters 2000, 331, 35.

[25] J.-C. Charlier, L. Arnaud, I. Avilov, M. Delgado, F. Demoisson, E. Espinosa, C. P. Ewels, A. Felten, J. Guillot, R. Ionescu, Nanotechnology 2009, 20, 375501.

[26] T. Prasomsri, D. Shi, D. E. Resasco, Chemical Physics Letters 2010, 497, 103.

[27] Z. Zanolli, R. Leghrib, A. Felten, J.-J. Pireaux, E. Llobet, J.-C. Charlier, ACS Nano 2011, 5, 4592 .

[28] J.-C. Charlier, Accounts of chemical research 2002, 35, 1063.

[29] A. Salehi-Khojin, F. Khalili-Araghi, M. A. Kuroda, K. Y. Lin, J.-P. Leburton, R. I. Masel, ACS nano 2010, 5, 153.

[30] a) B. Wang, J. C. Cancilla, J. S. Torrecilla, H. Haick, Nano letters 2014, 14, 933; b) G. Konvalina, H. Haick, Accounts of chemical research 2013, 47, 66.

[31] S. Kline, W. Reynolds, F. Schraub, P. Runstadler, Journal of Fluid Mechanics 1967, $30,741$.

[32] D. MacDougall, W. B. Crummett, Analytical Chemistry 1980, 52, 2242.

[33] a) D. M. Rudkevich, G. Hilmersson, J. Rebek, Journal of the American Chemical Society 1998, 120, 12216; b) D. M. Rudkevich, G. Hilmersson, J. Rebek, Journal of the American Chemical Society 1997, 119, 9911; c) P. J. Skinner, A. G. Cheetham, A. Beeby, V. Gramlich, F. Diederich, Helvetica Chimica Acta 2001, 84, 2146.

[34] United States Environmental Protection Agency, Nitrogen dioxide, http://www.epa.gov/air/nitrogenoxides/.

[35] J. Li, Y. Lu, Q. Ye, M. Cinke, J. Han, M. Meyyappan, Nano Letters 2003, 3, 929.

[36] K. Balasubramanian, K. Kern, Advanced Materials 2014, 26, 1154. 
[37] J. Pawliszyn, Handbook of Solid State Microextraction, Elsevier, London, UK, 2012.

[38] Humidity filtering tubes for PID detectors,

http://www.rae.nl/files/pdf/FeedsEnclosure-Humidity_Tube_II_LR_051507.pdf, accessed: April the 30th, 2015.

[39] T. Sainsbury, T. Ikuno, D. Okawa, D. Pacile, J. M. Frechet, A. Zettl, The Journal of Physical Chemistry C 2007, 111, 12992.

[40] X. Guo, Advanced Materials 2013, 25, 3397.

[41] Y. Zilberman, U. Tisch, G. Shuster, W. Pisula, X. Feng, K. Müllen, H. Haick, Advanced Materials 2010, 22, 4317. 


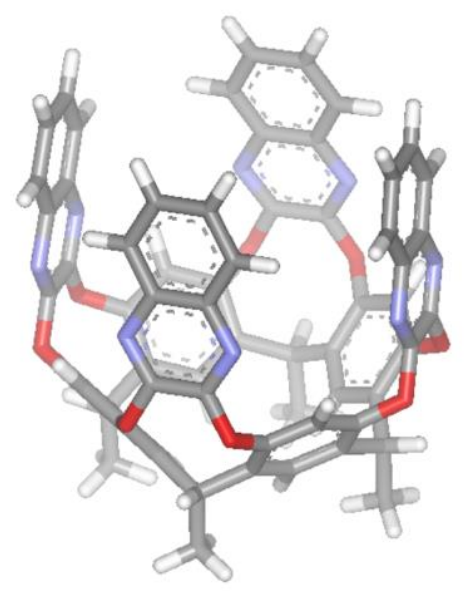

Figure 1. Energy-minimized (MM3 as implemented in Scigress v3.0) structure of cavitand 4 in vase conformation. Included molecule is omitted and cavitand legs $-\left(\mathrm{CH}_{2}\right)_{9}-\mathrm{S}-\left(\mathrm{CH}_{2}\right)_{9}-\mathrm{CH}_{3}$ are presented as methyl groups for clarity.

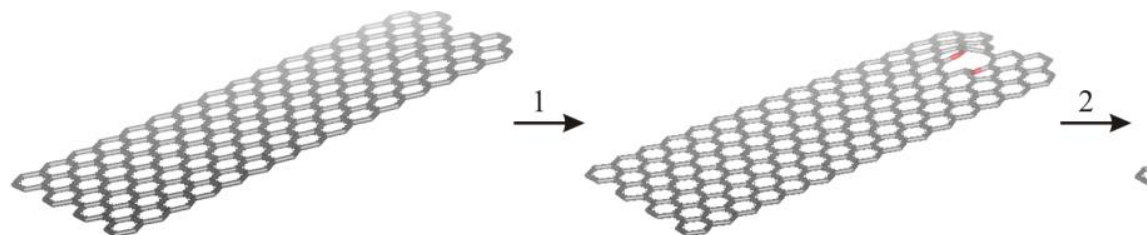

MWCNT

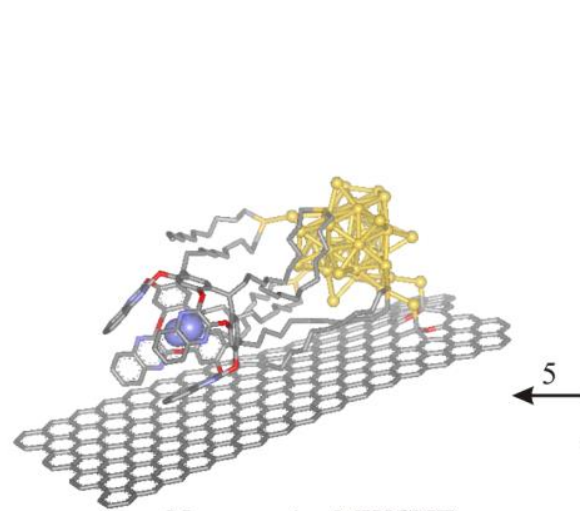

$\mathrm{N}_{2} \subset$ cav-Au-MWCNT
O-MWCNT

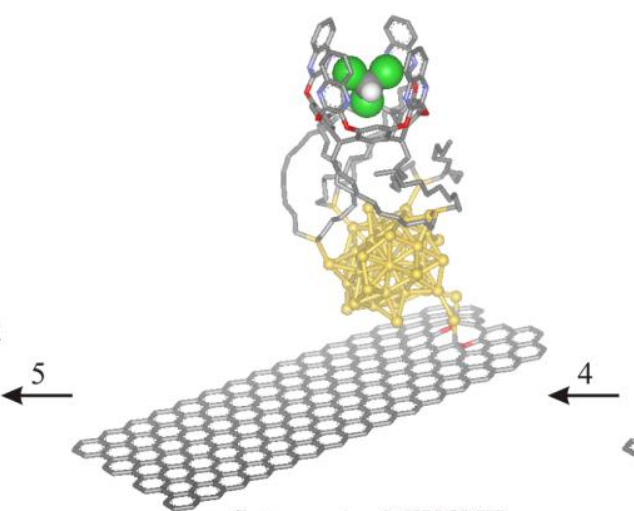

$\mathrm{S} \subset$ cav-Au-MWCNT

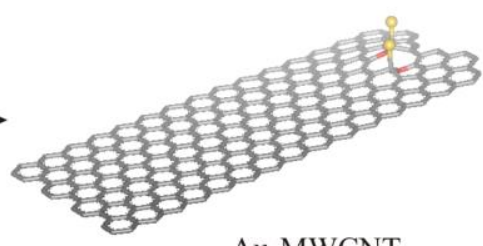

Au-MWCNT
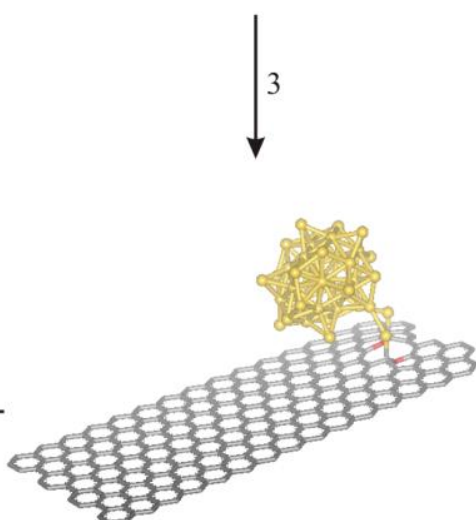

Au-MWCNT

Figure 2. Schematic representation of the preparation of the cav-Au-MWCNT material: (1) oxygen plasma treatment; (2) Au-RF-sputtering (formation of Au-nucleus); (3) AuRF-sputtering (growth of Au-nucleus and formation of Au-NP); (4) self-assembly of the cavitand 4 monolayer on the Au-NP surface by dipping the material in a chloroform (S) solution of the cavitand 4; (5) solvent removal (an air molecule, e.g. nitrogen, replaces chloroform (S) molecule from the cavitand interior). ${ }^{[22]}$ Nitrogen and chloroform 
molecules are presented as CPK models. Hydrogen atoms are omitted for clarity.

Symbol $\subset$ stands for "included in". Note: we hypothesize that upon chloroform removal, the cavitand legs are no longer solvated and the molecule collapses on the Au-MWCNT surface.

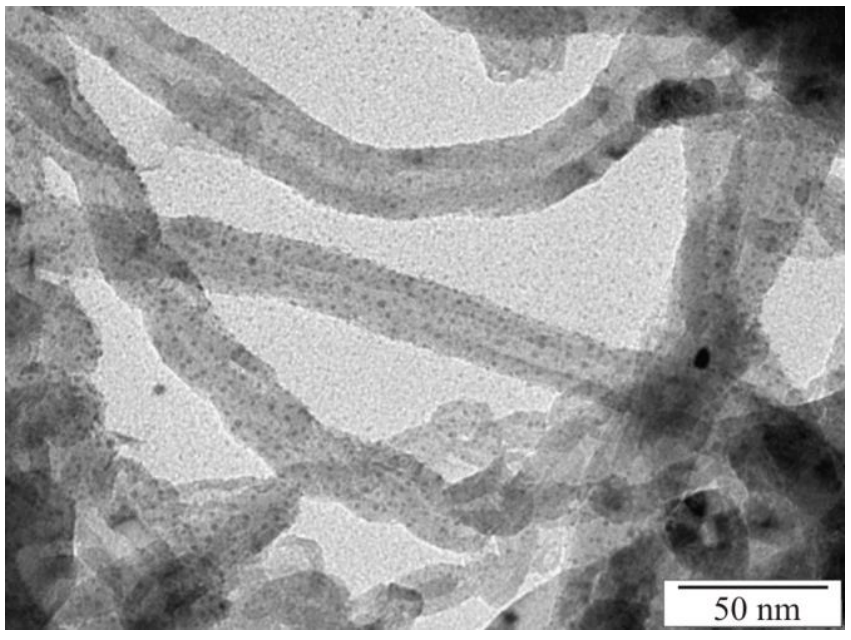

Figure 3. Typical TEM image of Au-MWCNTs. 

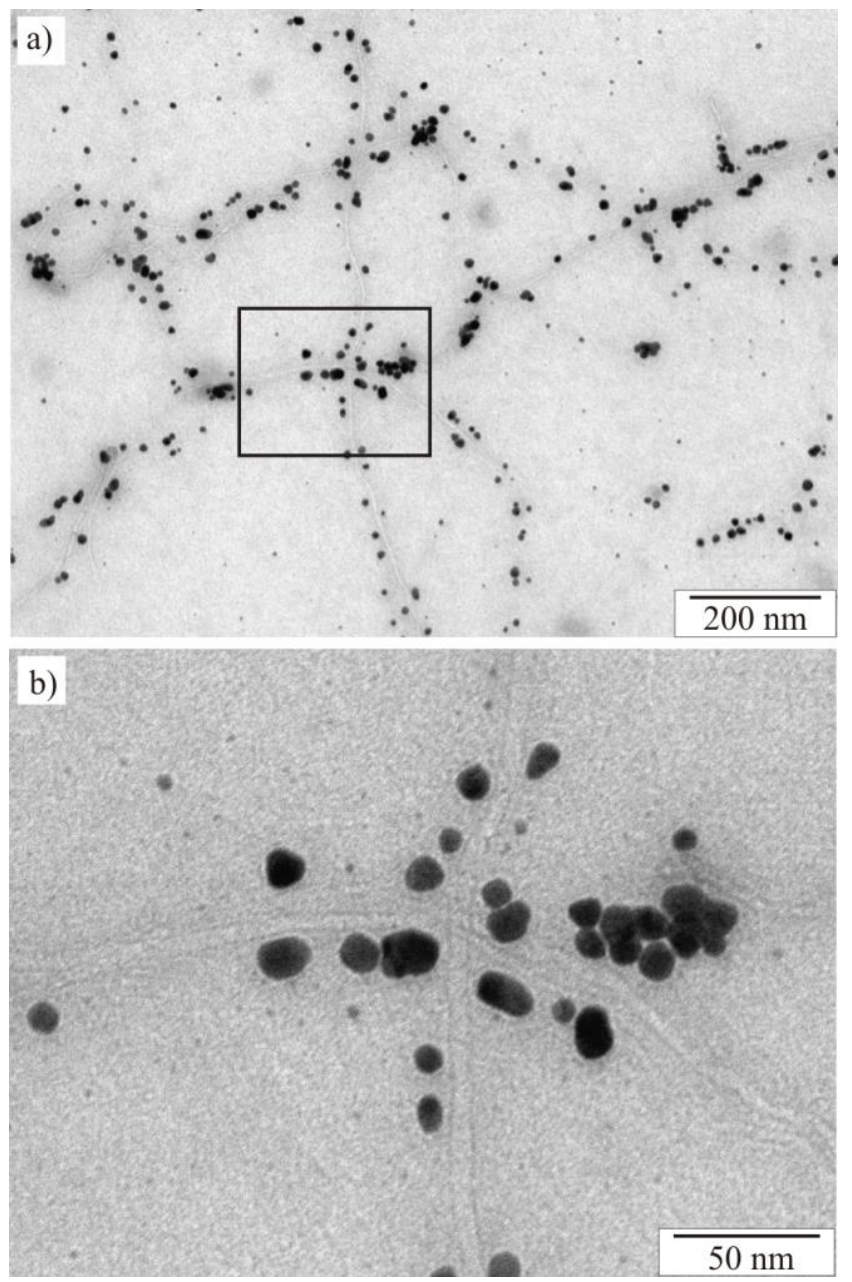

Figure 4. Typical TEM image of: a) cav-Au-MWCNTs and b) zoom-in of the selected area. 

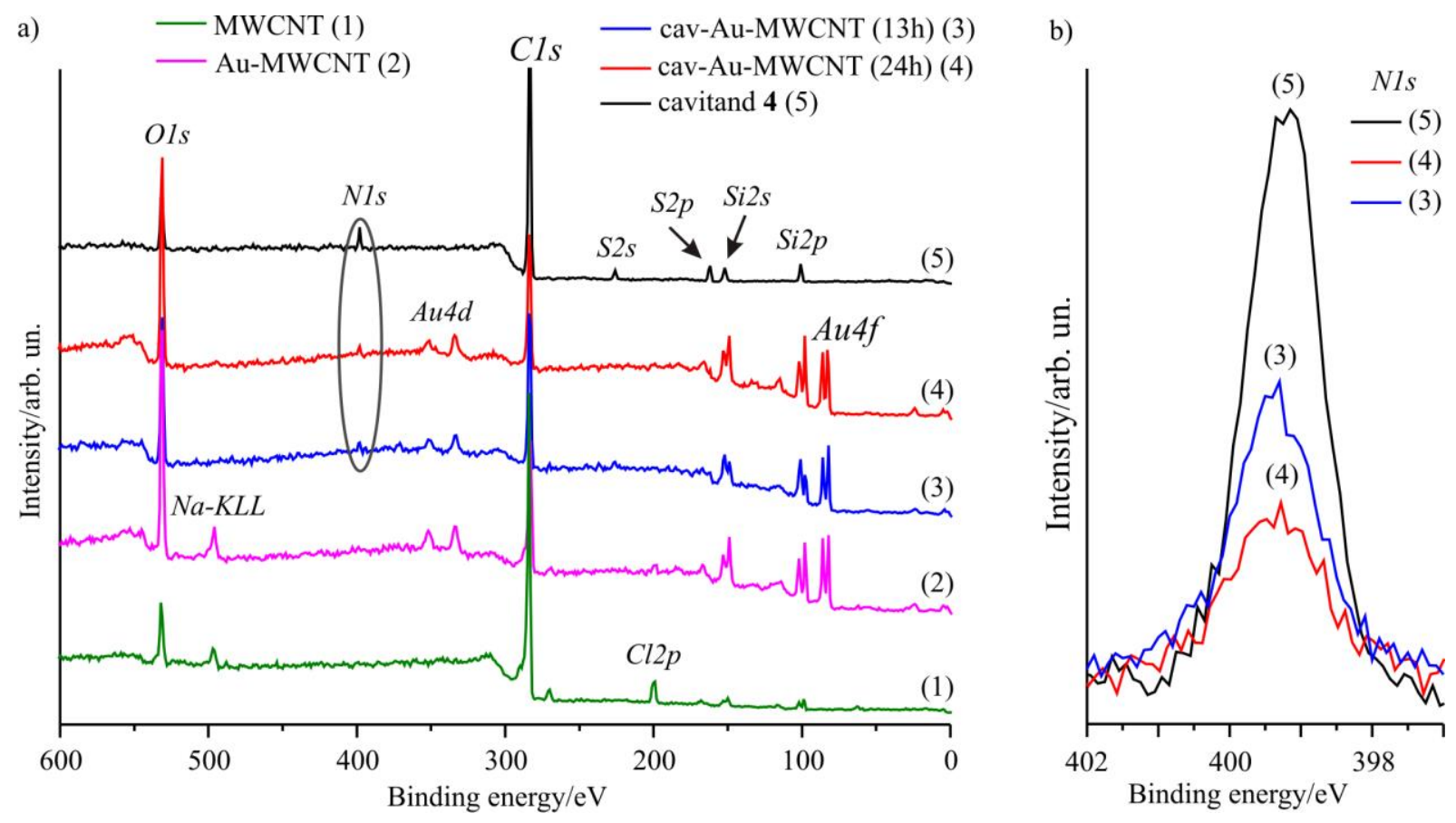

Figure 5. a) Survey spectra acquired for each step of the MWCNTs modification (1-4) and for the cavitand 4 (5). b) a zoom-in of $N_{1 s}$ core level spectra are plotted as acquired from cavitand 4 (5) and cav-Au-MWCNT samples (3 and 4). 

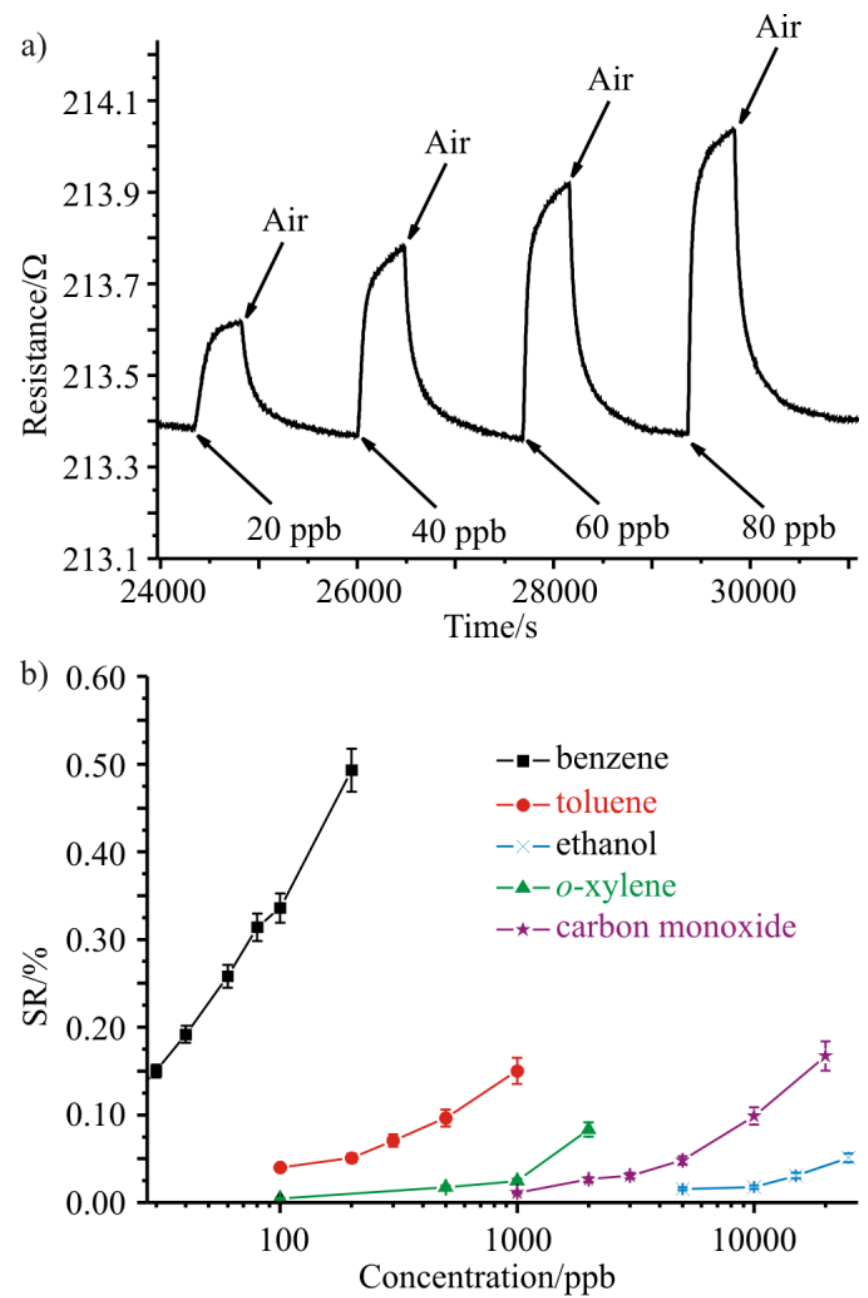

Figure 6. a) A typical cav-Au-MWCNT sensor resistance response in function of benzene concentration in air; b) The relative sensor response for different gas contaminants. In all experiments, we employed a gas flow of $200 \mathrm{~mL} \mathrm{~min}^{-1}$. 

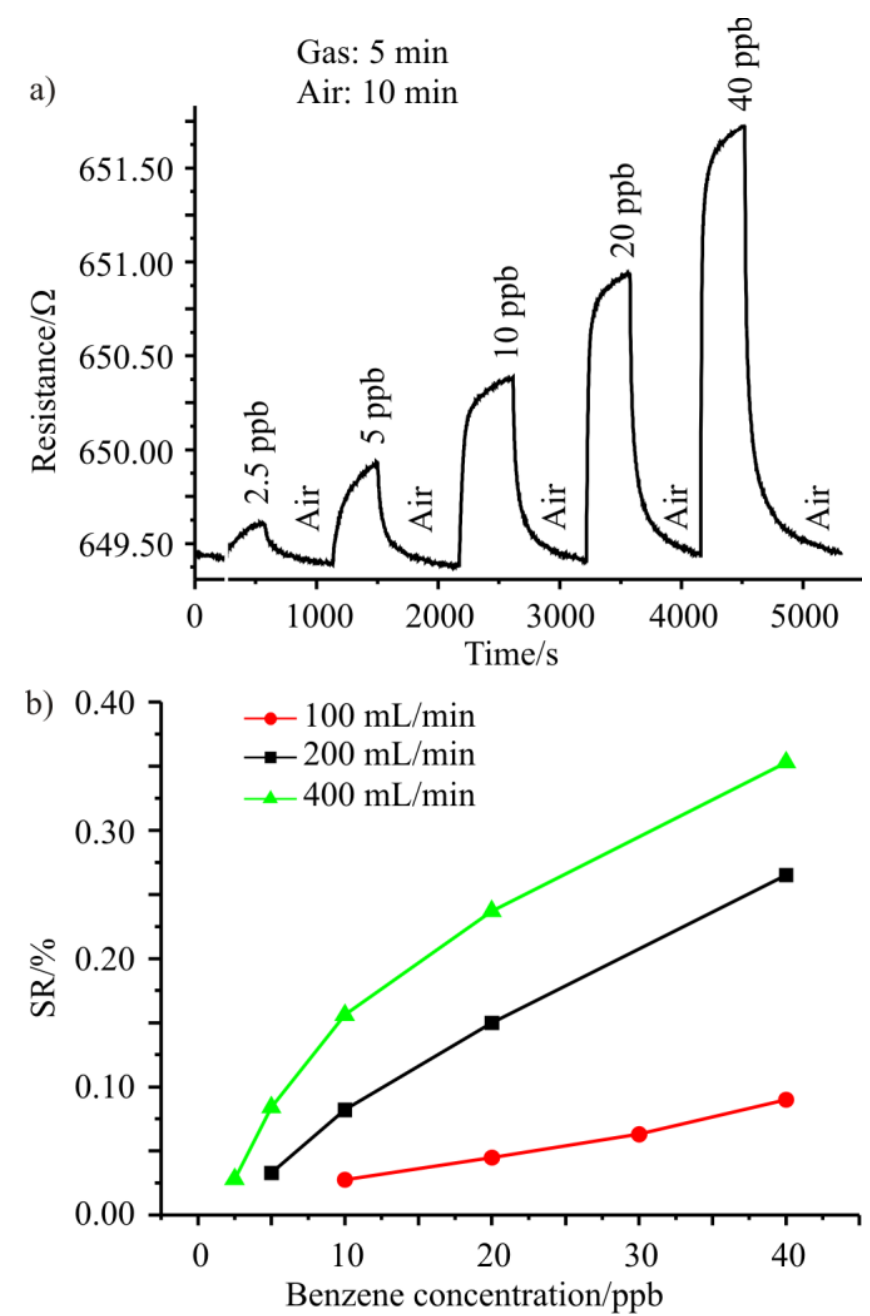

Figure 7. a) cav-Au-MWCNT sensor resistance response in function of benzene

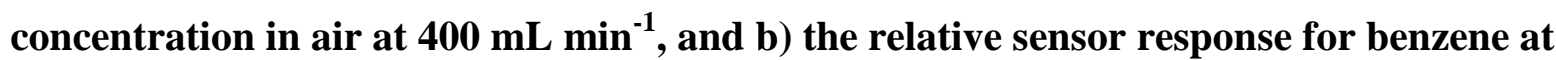
different gas flows. 


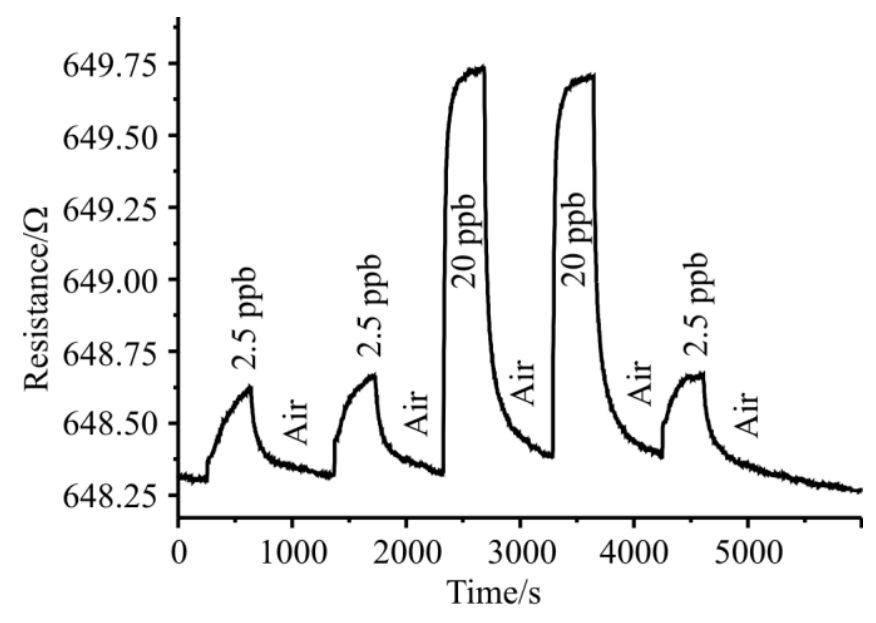

Figure 8. The cav-Au-MWCNT sensor resistance response in function of two benzene concentrations ( 2.5 and $20 \mathrm{ppb})$ exposed to sensor in a random order. 


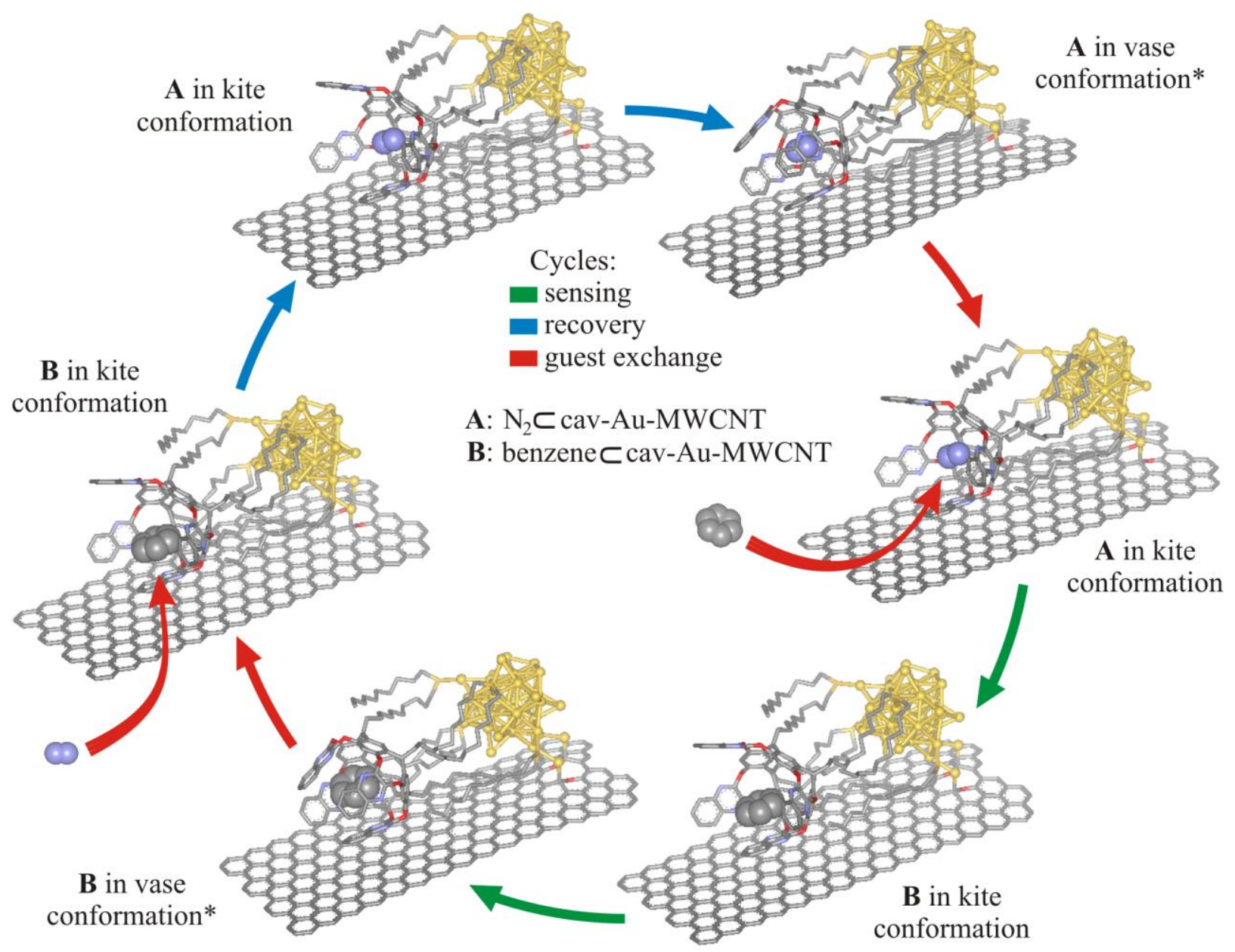

Figure 9. Proposed benzene sensing and recovery mechanism. Benzene and nitrogen molecules are shown as CPK models. Hydrogen atoms are omitted for clarity. Notes: * crucial structures in the sensing process. 


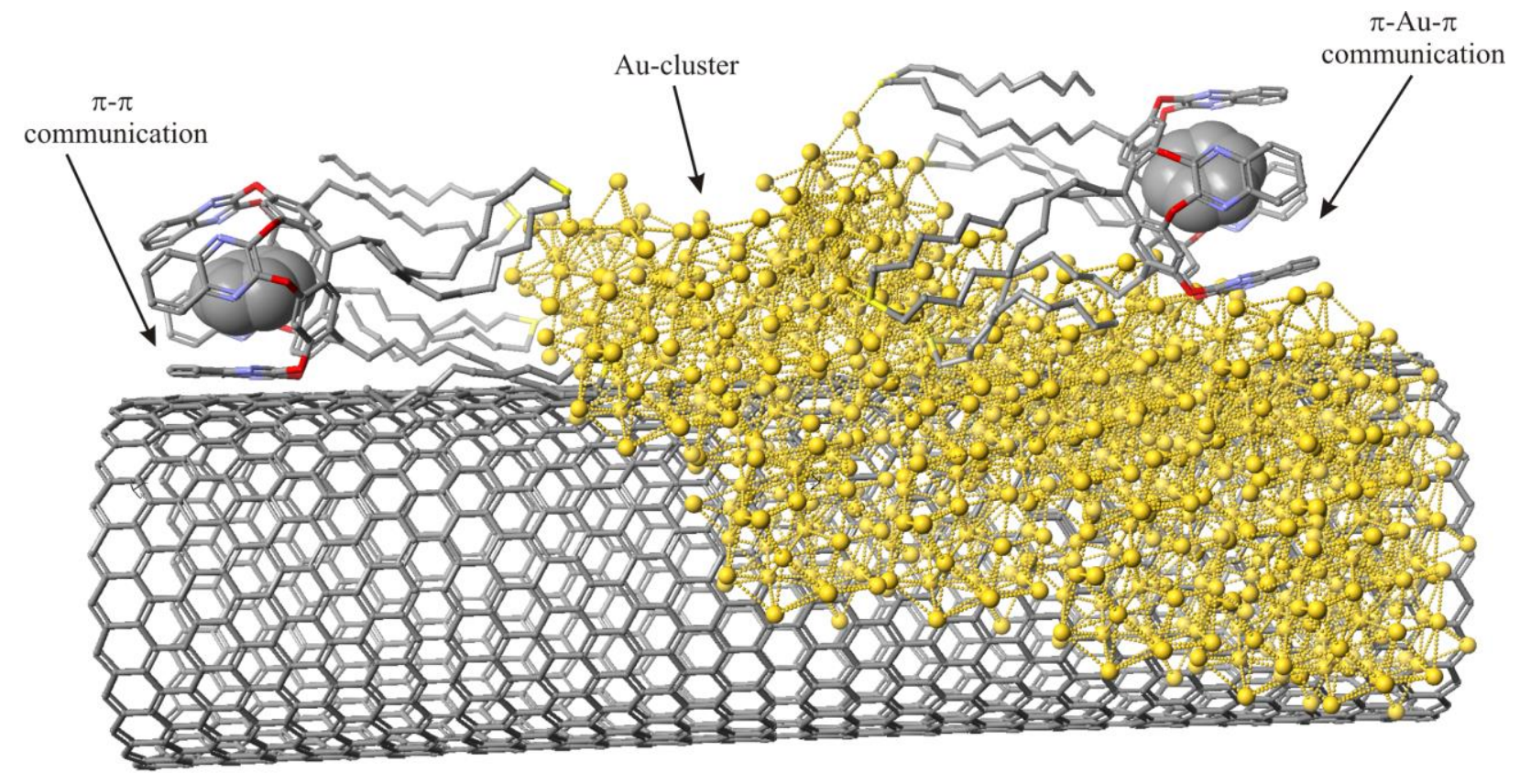

Figure 10. Representation of two proposed types of communication between the cavitand 4 and the Au-MWCNT. Benzene molecules are presented as CPK models. Hydrogen atoms are omitted for clarity. 